\title{
Hydroxycamptothecin mediates antiproliferative effects through apoptosis and autophagy in A549 cells
}

\author{
YANJIE WEI ${ }^{1}$, CHENHAO $^{2}{ }^{2}$, YUAN ZHANG ${ }^{1}$, HAILAN HE ${ }^{1}$, GUOZHI ZHANG ${ }^{3}$, \\ XIAOHUI HAO ${ }^{1}$, HELIANG LIU ${ }^{1}$, HONGLI WANG ${ }^{1,4}$ and WEI TIAN ${ }^{1}$ \\ ${ }^{1}$ Medical Research Center, North China University of Science and Technology, Tangshan, Hebei 063000; \\ ${ }^{2}$ Department of Oncology, Cangzhou Central Hospital, Cangzhou, Hebei 061000; \\ ${ }^{3}$ Department of General Surgery, North China University of Science and Technology Affiliated Hospital; ${ }^{4}$ Public \\ Health School, North China University of Science and Technology, Tangshan, Hebei 063000, P.R. China
}

Received January 19, 2017; Accepted November 2, 2017

DOI: $10.3892 / \mathrm{ol} .2018 .8107$

\begin{abstract}
Hydroxycamptothecin (HCPT) represents a new generation of anticancer drugs, with almost no side effects when used for the treatment of a number of types of cancer. Autophagy is becoming recognized as an important biological mechanism in human cancer, including lung cancer. However, the involvement of autophagy in the antiproliferative effects of HCPT on lung cancer remains unclear. In the present study, A549 cells, an accepted model of non-small cell lung cancer (NSCLC) cells, were employed. It was demonstrated that HCPT was able to suppress proliferation and induce apoptosis and autophagy in A549 cells. The molecular mechanism underlying HCPT-induced cell death was attributed to apoptosis and autophagy. Furthermore, it was demonstrated that an autophagy inhibitor, 3-methyladenine, accelerated HCPT-induced cell death in A549 cells. The results of the present study may lead to a deeper understanding of the molecular mechanism by which HCPT regulates NSCLC A549 cells. These results highlight the potential use of autophagy inhibitors in combination with traditional chemotherapy drugs for the treatment of lung cancer.
\end{abstract}

\section{Introduction}

Hydroxycamptothecin (HCPT) has few side effects in the treatment of various cancers and has been widely used

Correspondence to: Professor Hongli Wang, Public Health School, North China University of Science and Technology, 57 Jianshenan Road, Tangshan, Hebei 063000, P.R. China

E-mail: tsruoshui@163.com

Professor Wei Tian, Medical Research Center, North China University of Science and Technology, 57 Jianshenan Road, Tangshan, Hebei 063000, P.R. China

E-mail: twhzm@aliyun.com

Key words: lung cancer, non-small cell lung cancer, autophagy, apoptosis, autophagy inhibitor, hydroxycamptothecin clinically (1-3). HCPT can inhibit proliferation and induce apoptosis in some types of cancer treatment, including prostate, colon and ovarian cancer (4-6). However, the underlying molecular mechanism by which HCPT affects the development of lung cancer has not yet been elucidated.

In the 21st Century, lung cancer has accounted for a marked proportion of morbidity and mortality worldwide according to the American Cancer Society (7). Small-cell lung carcinoma (SCLC) and non-SCLC (NSCLC) are the primary types of lung cancer, $85-90 \%$ of lung cancer is NSCLC (8). Among those patients with advanced NSCLC and those undergoing first-line platinum-based double-agent chemotherapy, the remission rate is between 30 and $40 \%$. In addition, the median survival time is reported to be between 31 and 40 weeks, and the 1-year survival rate is between 30 and $40 \%$ (9). Therefore, there is an urgency to understand the key issues regarding alternative therapeutic approaches for treating NSCLC.

Autophagy serves a pivotal function in the physiological and pathological processes. It eliminates misfolded aggregated proteins to maintain cellular homeostasis $(10,11)$. Nucleation and elongation of the isolation membrane are the two major processes in the autophagosome formation. At first, the formation of the initial film nucleation stage requires a kinase complex including Beclin-1, a B-cell lymphoma 2 (Bcl-2) homology domain 3-only protein, which is frequently used as a marker for monitoring autophagy. Subsequently, the cytosolic protein light chain 3 (LC3)I is conjugated to phosphatidylethanolamine, forms LC3II and participates in membrane elongation (12-15). In addition, autophagy pathways have also been reported to participate in anticancer drug-induced cell death, such as 5-fluorouracil and rapamycin $(16,17)$. Notably, it has been demonstrated that the appropriate modification of autophagy is able to accelerate the process of apoptosis and enhance the curative effect of chemotherapy (18-20). However, the effects of autophagy on the ability of HCPT to inhibit the proliferation of lung cancer cells remain unknown.

\section{Materials and methods}

Chemicals and antibodies. 3-Methyladenine (3-MA) and rapamycin were purchased from Sigma; Merck KGaA 
(Darmstadt, Germany). A Cyto-ID autophagy detection kit was purchased from Enzo Life Sciences, Inc. (Farmingdale, NY, USA; cat. no. ENZ-51031-K200). HCPT was purchased from Bailingwei Technology Co., Ltd. (Beijing, China) and an MTT cell viability assay kit was purchased from Zhejiang Tianshun Biotechnology Co., Ltd. (Zhejiang, China; http://tianshunbiotech.com/index_en.asp). An Annexin V-propidium iodide (PI) apoptosis kit was purchased from Yeasen Biotechnology Co., Ltd. (Shanghai, China). Rabbit polyclonal anti-Beclin-1 (cat. no. 4122), rabbit polyclonal anti-phosphorylated mammalian target of rapamycin (p-mTOR) (cat. no. 5536), rabbit polyclonal anti-Bcl-2-associated X protein (Bax) (cat. no. 2772), rabbit polyclonal anti-Bcl-2 (cat. no. 2876), rabbit polyclonal anti-GAPDH (cat. no. 5174), goat anti-rabbit immunoglobulin secondary antibody (cat. no. 14708), Tubulin antibody (cat. no. 2146) were purchased from Cell Signaling Technology, Inc. (Danvers, MA, USA); Rabbit polyclonal anti-LC3 (cat. no. L7543) were purchased from Sigma; Merck KGaA (Darmstadt, Germany).

Cell culture and treatments. The A549 NSCLC cells were obtained from the Chinese Academy of Sciences (Beijing, China) and maintained in RPMI-1640 medium (Shanghai Haoran Biological Technology Co., Ltd., Shanghai, China) supplemented with $10 \%$ fetal bovine serum (FBS; Shanghai Haoran Biological Technology Co., Ltd.) at $37^{\circ} \mathrm{C}$ in a humidified atmosphere containing $5 \% \mathrm{CO}_{2}$. When cells reached $70-80 \%$ confluence, $(0-400 \mu \mathrm{M}) \mathrm{HCPT}$ was added to the medium for $24 \mathrm{~h}$.

Cell viability assay. In brief, A549 cells were plated in a 96-well plate at $5 \times 10^{4}$ cells/well and were treated with $(0-400 \mu \mathrm{M})$ HCPT. After $24 \mathrm{~h}, 10 \mu \mathrm{l} 5 \mathrm{mg} / \mathrm{ml}$ MTT solution was added to each well prior to incubation at $37^{\circ} \mathrm{C}$ for an additional $4 \mathrm{~h}$. Following careful removal of the medium, $150 \mu \mathrm{l}$ MTT solvent (DMSO) was added to each well. Cells were protected from light and mixed on an orbital shaker $(80 \mathrm{rpm})$ for $15 \mathrm{~min}$. The absorbance values were read at $590 \mathrm{~nm}$, with a reference filter of $620 \mathrm{~nm}$. Each experiment was performed in triplicate.

Apoptosis assay. A549 cells were grown to 70-80\% confluence and HCPT group A549 cells were treated with $(0-400 \mu \mathrm{M})$ HCPT for $24 \mathrm{~h},(5 \mathrm{mM}) 3$-MA group A549 cells were treated with (5 mM) 3-MA for $1 \mathrm{~h}$ and (50-400 $\mu \mathrm{M}) \mathrm{HCPT}+(5 \mathrm{mM})$ 3-MA group A549 cells were treated with (5 mM) 3-MA for $1 \mathrm{~h}$ then were treated with $(50-400 \mu \mathrm{M}) \mathrm{HCPT}$ for $24 \mathrm{~h}$. Analysis of apoptosis in cells stained with fluorescein isothiocyanate (FITC) Annexin V and propidium iodide (PI) was performed using a flow cytometer and Cell Quest Pro software version 5.1 (BD Biosciences, San Jose, CA, USA). Each experiment was performed in triplicate.

Determination of autophagosome formation using Cyto-ID staining. The cell nucleus was stained blue by Hoechst 33342 $(5 \mu \mathrm{g} / \mathrm{ml})$ in the dark for $30 \mathrm{~min}$ at $37^{\circ} \mathrm{C}$ and Cyto-ID Green dye (diluted in 5\% FBS at 1:1,000) was employed to selectively label autolytic enzyme bodies and indicate autophagy at $37^{\circ} \mathrm{C}$ in the dark for $30 \mathrm{~min}$, which are expressed as green dots as described in a previous study (21). A Cyto-ID autophagy detection kit was employed to analyze autophagy. In brief,
A549 cells were washed with $1 \mathrm{X}$ assay buffer containing $5 \% \mathrm{FBS}$ and cells were incubated in Cyto-ID solution at $37^{\circ} \mathrm{C}$ in the dark for $30 \mathrm{~min}$. Finally, all samples were visualized by laser-scanning confocal microscopy (FV1000; Olympus Corporation, Tokyo, Japan), (confocal microscope image $\mathrm{x} 40$ magnification).

Western blot analysis. Whole cell lysate was prepared with lysis using Triton X-100/glycerol buffer, containing $50 \mathrm{mM}$ Tris-HCl (pH 7.4), 4 mM EDTA, 2 mM EGTA, and $1 \mathrm{mM}$ dithiothreitol, supplemented with $1 \%$ Triton X-100, $1 \%$ SDS, and protease inhibitors, and then separated on a SDS-PAGE gel and transferred to PVDF membrane. Western blot analysis was performed using appropriate primary antibodies and horseradish peroxidase-conjugated suitable secondary antibodies, followed by detection with enhanced chemiluminescence (Pierce Chemical). A total of $30 \mathrm{mg}$ protein lysate (the protein determination method adopt BCA) was separated by SDS-PAGE (8-13\%) and then transferred onto a polyvinylidene difluoride membrane (Bio-Rad Laboratories, Inc., Hercules, CA, USA). Membranes were incubated overnight at $4^{\circ} \mathrm{C}$ with primary antibodies against LC3 (dilution, 1:1,000), Beclin-1 (dilution, 1:1,000), p-mTOR (dilution, 1:1,000), Bax (dilution, 1:1,000), Bcl-2 (dilution, 1:1,000), GAPDH (dilution, 1:1,000) and Tubulin (dilution, 1:1,000), prior to incubating membranes with goat anti-rabbit immunoglobulin secondary antibody (dilution, 1:1,000) for $2 \mathrm{~h}$ at room temperature. The bands were visualized by enhanced chemiluminescence (Genshare, Shaanxi, China). Image J software version 1.4.3.67 (National Institutes of Health, Bethesda, MD, USA) was employed to quantify protein expression levels. GAPDH or Tubulin $(\mathrm{Tu})$ were used as loading controls.

Statistical analysis. Data were analyzed using SPSS software (version 21.0; IBM Corp., Armonk, NY, USA). Data are expressed as the mean \pm standard deviation. One-way analysis of variance followed by a Least Significance Differences (LSD) post-hoc testing was used to examine differences between groups. $\mathrm{P}<0.05$ was considered to indicate a statistically significant difference.

\section{Results}

HCPT inhibits cell proliferation and induces apoptosis in A549 cells. As presented in Fig. 1A, treatment with $(0-400 \mu \mathrm{M})$ HCPT resulted in a dose-dependent decrease in A549 cell viability. In order to determine whether HCPT induced apoptosis of A549 cells, the expression of the apoptosis-specific proteins Bax and $\mathrm{Bcl}-2$ was determined in $(0-400 \mu \mathrm{M})$ HCPT-treated A549 cells by western blot analysis (Fig. 1B). The results indicated that HCPT downregulates Bcl-2 expression and increases Bax expression in vitro. Furthermore, the Bcl-2/Bax ratio was decreased in response to HCPT (Fig. 1B). Similar results were acquired using flow cytometric analysis (Fig. 1C), Annexin ${ }^{+} \mathrm{PI}^{+}$represent apoptosis. Taken together, these results suggest that HCPT induces apoptotic cell death in A549 cells.

HCPT induces autophagy in A549 cells. In order to determine whether HCPT was able to induce autophagy in A549 cells, a 
A

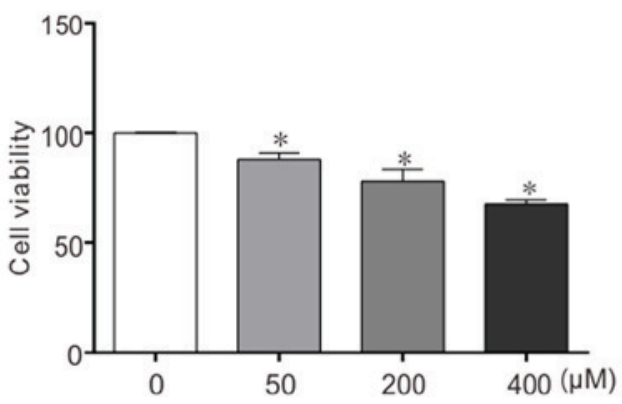

B

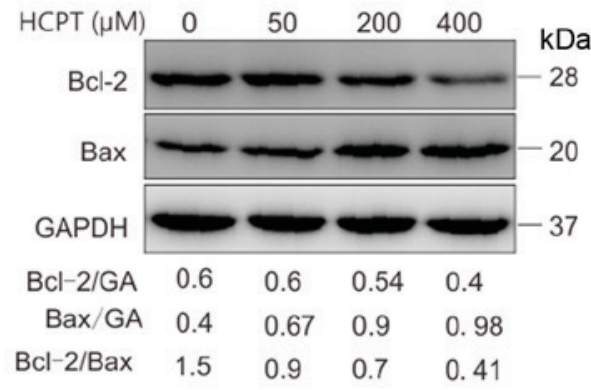

C

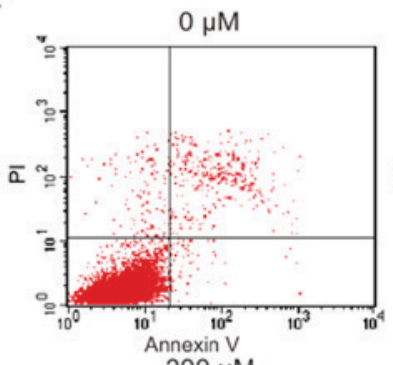

$200 \mu \mathrm{M}$

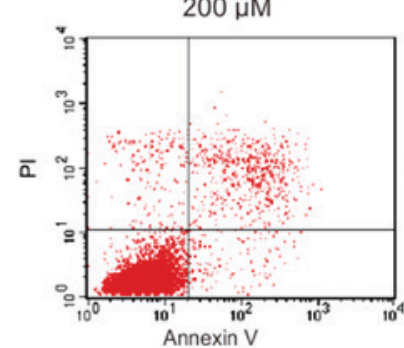

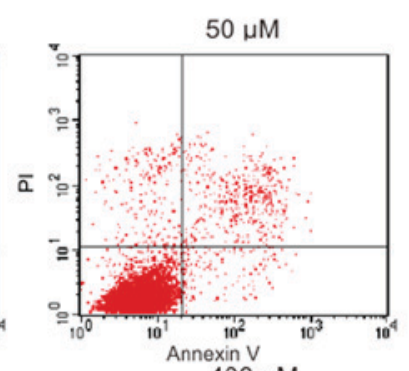

$400 \mu \mathrm{M}$

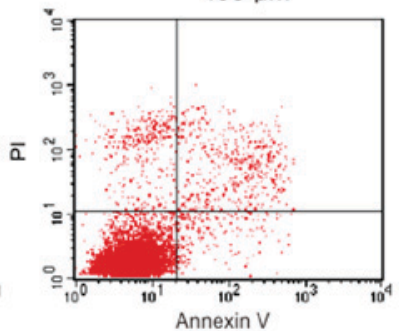

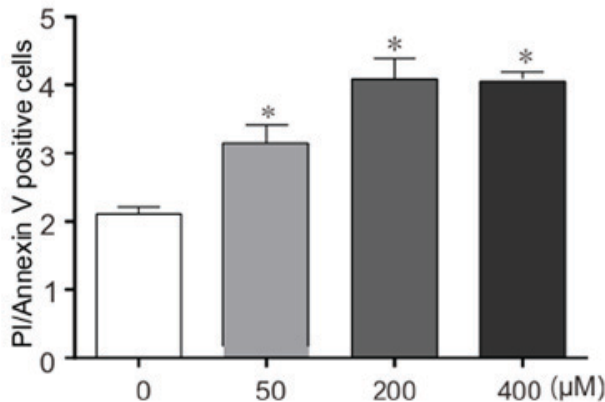

Figure 1. HCPT inhibits cell viability and induces apoptosis in A549 cells. (A) Cell viability in A549 cells treated with various concentrations of (0, 50, 200 and $400 \mu \mathrm{M}$ ) HCPT using an MTT assay. (B) Expression of apoptosis-associated proteins Bcl-2 and Bax determined using western blot analysis. GAPDH (GA) was used as a loading control. The band intensities of the Bcl-2/Bax ratio were normalized to GAPDH (GA). (C) Apoptosis (Annexin ${ }^{+} \mathrm{PI}^{+}$represent apoptosis) in A549 cells treated with various concentrations of (0, 50, 200 and $400 \mu \mathrm{M}) \mathrm{HCPT}$ assessed using Annexin V/PI staining and flow cytometry. Results are expressed as the mean \pm standard deviation. In total, 10 independent experiments were performed. "P<0.05 vs. ( $0 \mu \mathrm{M})$ HCPT (control). HCPT, hydroxycamptothecin; Bcl-2, B-cell lymphoma 2; Bax, Bcl-2-associated X protein; PI, propidium iodide.

Cyto-ID autophagy detection kit was employed. As presented in Fig. 2, the number of Cyto-ID-positive cells gradually increased with increasing concentrations of HCPT treatment in A549 cells. In order to further verify this result, the expression of autophagy-associated proteins, including LC3, Beclin-1 and p-mTOR, was detected in A549 cells treated with HCPT (RPMI-1640 medium with 0-400 $\mu \mathrm{M}$ HCPT) by western blot analysis. The results indicated that HCPT increased the conversion of LC3I into LC3II (Fig. 3A) and increased Beclin-1 protein expression (Fig. 3B), but decreased the expression of p-mTOR (Fig. 3C), suggesting that HCPT induces autophagy in A549 cells.

Effect of autophagy inhibitors. Autophagy is able to be inhibited by activation of the phosphoinositide 3-kinase signaling pathway (22). In order to further prove that HCPT is able to induce an increase in autophagy, cells were treated with an autophagy inhibitor (3-MA) prior to treatment with HCPT. A549 cells were treated with (5 mM) 3-MA, prior to $(200 \mu \mathrm{M}) \mathrm{HCPT}$ treatment for $1 \mathrm{~h}$ (Fig. 4). The results from this experiment demonstrated that the combination of 3-MA and HCPT significantly decreased cell viability (Fig. 5A) and the $\mathrm{Bcl}-2 / \mathrm{Bax}$ ratio decreased (Fig. 5B) and increased apoptosis (Fig. 5C) (Annexin ${ }^{+} \mathrm{PI}^{+}$represent apoptosis) in response to 3-MA and $200 \mu \mathrm{M}$ HCPT treatment in A549 cells. These results suggested that inhibition of autophagy decreased cell viability and increased apoptosis induced by HCPT in A549 cells.

\section{Discussion}

Uncontrolled proliferation and deregulated apoptosis are important features of malignant tumor cells, and there are a number of anticancer drugs that target tumor cell proliferation and induce apoptosis (23-25). The Bcl-2 family proteins serve an important function in regulating apoptosis. For example, $\mathrm{Bcl}-2$ is the main inhibitor of apoptosis and Bax is the main promoter of apoptosis in the Bcl-2 family. Furthermore, Bcl-2 and Bax regulate the release of apoptotic activators, including cytochrome c, to affect the state of cells by controlling the permeability of mitochondrial membrane (26). The Bax dimer opens the channel on the membrane in order to increase its permeability, Bcl-2 and Bax form a heteropolymer which reduces permeability (27), when Bax forms a homologous dimer, it induces apoptosis. The Bax-Bcl-2 allodimer inhibits cell apoptosis (28). Furthermore, Bcl-2 and Bax regulate tumor cell apoptosis (29). The Bcl-2/Bax ratio is associated with tumor occurrence and development $(30,31)$. In the present study, Bax 


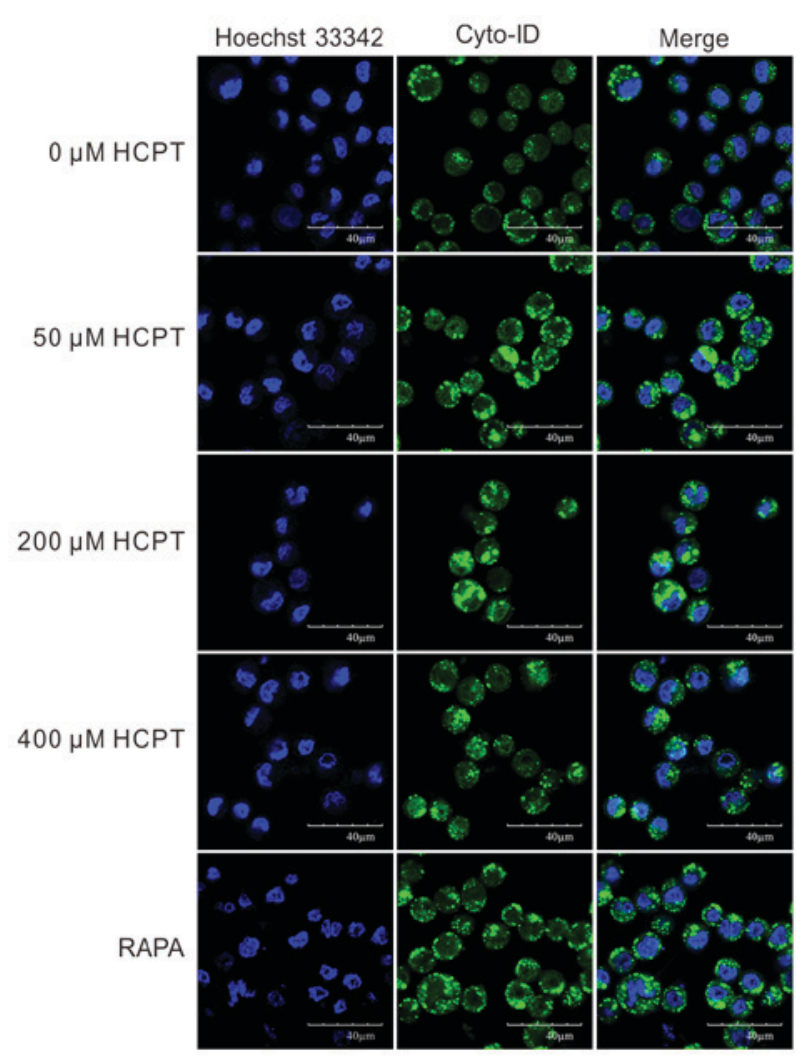

Figure 2. HCPT treatment increases autophagy in A549 cells. Cyto-ID staining of A549 cells exposed to $(0,50,200$ and $400 \mu \mathrm{M})$ HCPT. Hoechst 33342 dye stained the nucleus (blue), Cyto-ID stained the autophagic cells (green). Magnification, $x 40 ; n=8$. HCPT, hydroxycamptothecin; RAPA, rapamycin.

and Bcl-2 protein levels were assessed by western blot analysis. The results indicated that HCPT decreased Bcl-2 protein levels and increased Bax protein levels. Furthermore, the Bcl-2/Bax ratio was decreased in response to HCPT treatment. Flow cytometric analysis also confirmed these results, suggesting that HCPT induces apoptotic cell death in A549 cells. In addition, dose-dependent concentrations of $(0-400 \mu \mathrm{M})$ HCPT decreased cell viability of A549 cells as determined using an MTT assay. Taken together, the results of the present study suggest that HCPT inhibits cancer development by preventing tumor cell proliferation and inducing apoptosis.

The results of the present study indicate that HCPT induces autophagy in A549 cells and that by targeting autophagy using 3-MA, an autophagy inhibitor, the cells become more sensitive to HCPT treatment. Autophagy is responsible for maintaining the steady state of cells by degrading misfolded proteins and eliminating damaged organelles (32). However, evidence suggests that autophagy can lead to cell death via a process distinct from apoptosis (33), termed autophagic cell death. A number of anticancer drugs contribute to the antitumor process by inducing autophagy and apoptosis at the same time (34-36). It is important to note that a number of factors may induce autophagy, including hypoxia, DNA damage and damaged organelles $(36,37)$.

A growing body of evidence suggest a possible function of autophagy in controlling pathogens (38). In response to chemotherapy, autophagy-deficient tumors fail to elicit an anticancer immune (39). Therefore, future research should consider the cell context-specific functions of autophagy.

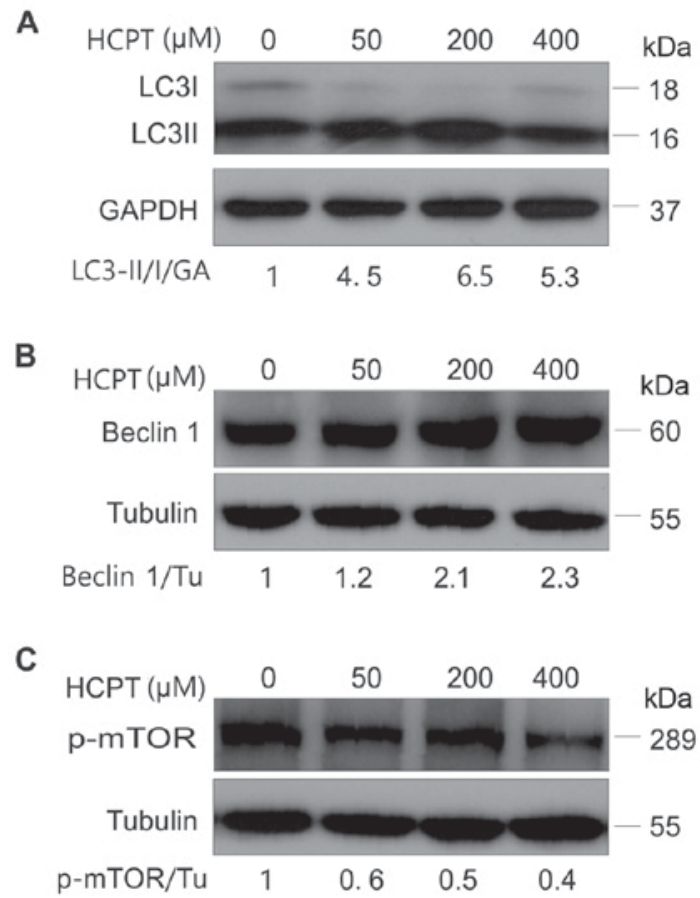

Figure 3. HCPT induces autophagic activity in A549 cells. (A) Western blot analysis of expression levels of LC3I/LC3II conversion, (B) Beclin-1 and (C) p-mTOR in A549 cells treated with $(0,50,200$ and $400 \mu \mathrm{M}) \mathrm{HCPT}$. Tubulin (Tu) or GAPDH (GA) was used as the loading control. Results are expressed as the mean \pm standard deviation. HCPT, hydroxycamptothecin; LC3, light chain 3; p-mTOR, phosphorylated mammalian target of rapamycin; Bax. Bcl-2-associated X protein; Bcl-2, B-cell lymphoma 2.

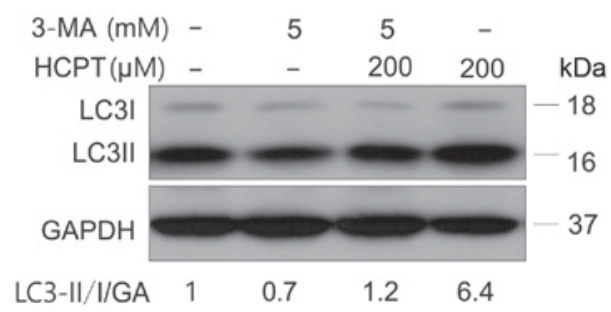

Figure 4. Effect of combined treatment with 3-MA and HCPT in A549 cells. HCPT group A549 cells were treated with $(0$ and $200 \mu \mathrm{M})$ HCPT for $24 \mathrm{~h}$, (5 mM) 3-MA group A549 cells were treated with $(5 \mathrm{mM}) 3$-MA for $1 \mathrm{~h}$ and $(50-200 \mu \mathrm{M}) \mathrm{HCPT}+(5 \mathrm{mM}) 3-\mathrm{MA}$ group A549 cells were treated with $(5 \mathrm{mM}) 3-\mathrm{MA}$ for $1 \mathrm{~h}$ then were treated with $(200 \mu \mathrm{M}) \mathrm{HCPT}$ for $24 \mathrm{~h}$. Expression levels of LC3I/LC3II conversion were analyzed using Western blotting. GAPDH (GA) was used as a loading control. HCPT, hydroxycamptothecin; 3-MA, 3-methyladenine.

The results of the present study indicated that exposing A549 cells to HCPT significantly increases autophagy. Treatment with an autophagy inhibitor (3-MA) led to a statistically significant decrease in viability and increased apoptosis in A549 cells in response to HCPT treatment. Therefore, inhibiting autophagy may decrease the viability and apoptosis of A549 cells treated with HCPT. Combining autophagy inhibitors with HCPT may enhance the efficacy of HCPT for treating lung cancer. The results of a recent study suggested that HCPT confers antitumor efficacy on HeLa cells via activating autophagy and mediating apoptosis in cervical cancer (40), which is also consistent with the results of the present study. Nevertheless, it is worth mentioning that the ratio of LC3II/I in the $200 \mu \mathrm{M}$ HCPT group was increased 

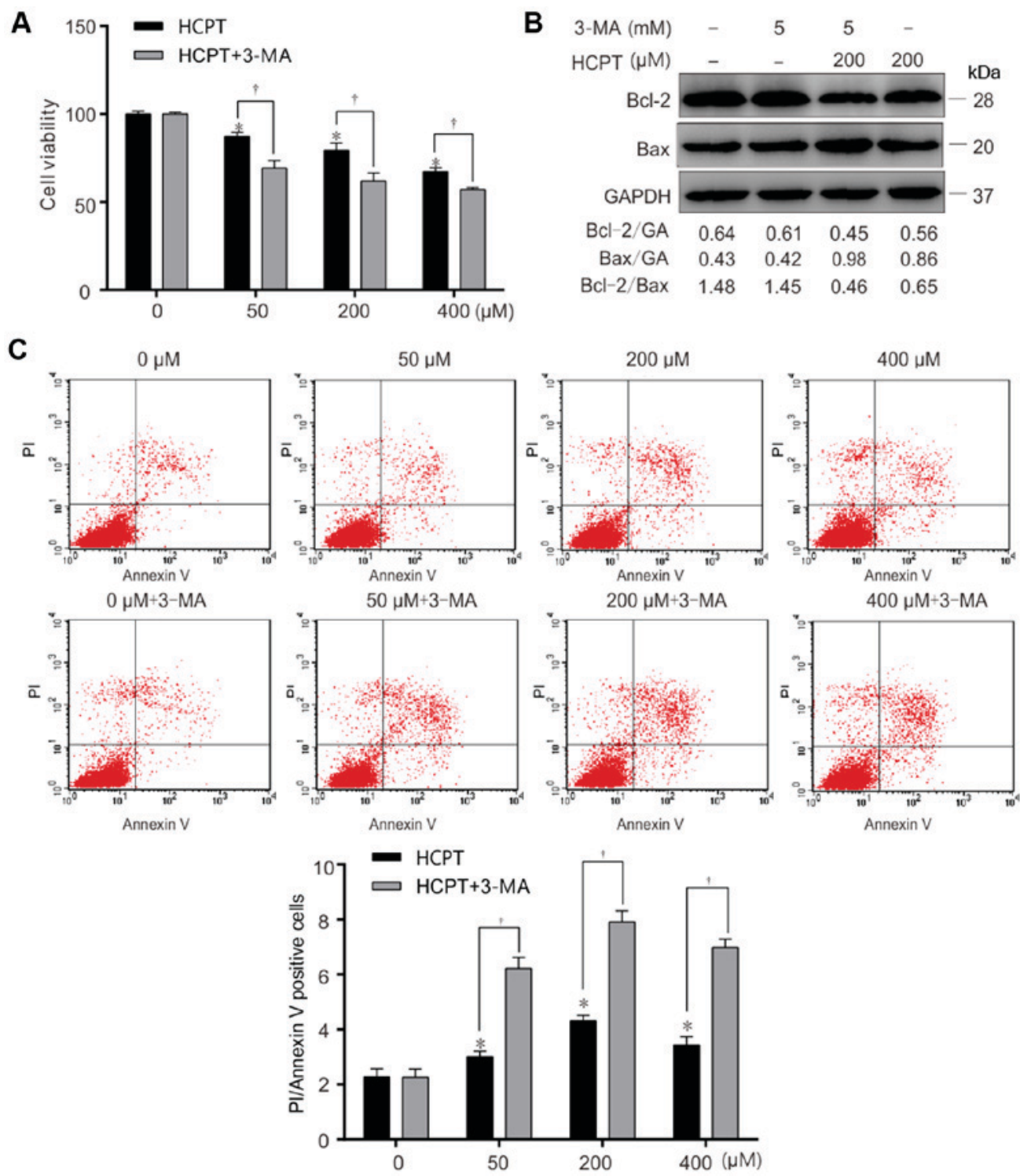

Figure 5. Inhibition of autophagy accelerates HCPT-induced apoptotic cell death in A549 cells. A549 cells were exposed to $(0,50,200$ or $400 \mu \mathrm{M}) \mathrm{HCPT}$ with or without 3-MA $(5 \mathrm{mM})$, and harvested at $24 \mathrm{~h}$. (A) Relative cell viability of A549 cells treated with $(0,50,200$ or $400 \mu \mathrm{M}) \mathrm{HCPT}$, (5 mM) 3-MA or with $(0,50,200$ or $400 \mu \mathrm{M}) \mathrm{HCPT}+(5 \mathrm{mM}) 3-\mathrm{MA}$, determined using an MTT assay. (B) Apoptosis determined in A549 cells which were treated with (0, 50, 200 or $400 \mu \mathrm{M}) \mathrm{HCPT},(5 \mathrm{mM}) 3$-MA or with $(0,50,200$ or $400 \mu \mathrm{M}) \mathrm{HCPT}+(5 \mathrm{mM}) 3-\mathrm{MA}$, using Annexin V/PI staining. (C) Western blot analysis of the Bcl-2/Bax ratio in A549 cells which were treated with $(0$ or $200 \mu \mathrm{M}) \mathrm{HCPT},(5 \mathrm{mM}) 3-\mathrm{MA}$ or $(0$ or $200 \mu \mathrm{M}) \mathrm{HCPT}+(5 \mathrm{mM}) 3-\mathrm{MA}$. GAPDH (GA) was used as a loading control. Results are expressed as the mean \pm standard deviation. ${ }^{*} \mathrm{P}<0.05$ vs. ( $\left.0 \mu \mathrm{M}\right)$ HCPT (control); ${ }^{\circ} \mathrm{P}<0.05$ vs. $(0,50,200$ or $400 \mu \mathrm{M}) \mathrm{HCPT}$. HCPT, hydroxycamptothecin; Bax, Bcl-2-associated X protein; Bcl-2, B-cell lymphoma 2; 3-MA, 3-methyladenine.

compared with that of the $400 \mu \mathrm{MHCPT}$ group. Similarly, the rate of change in the growth inhibition and apoptosis in the $200 \mu \mathrm{M}$ HCPT+3-MA group, relative to the $200 \mu \mathrm{M}$ HCPT group, was increased compared with that of the respective $400 \mu \mathrm{M}$ HCPT groups. These data suggest that the ability of HCPT to enhance autophagy in A549 cells is HCPT dose-dependent and that autophagy inhibition combined with $200 \mu \mathrm{M}$ HCPT treatment may be optimal for the treatment of lung cancer.

Autophagy has a dual function in tumorigenesis (41). Cancer is a complex disease, and autophagy serves different roles in patients depending on the type of cancer. Therefore, modulation of autophagy as a therapeutic strategy has a different sensitivity between the various types of cancer (42). Chemotherapy also serves an important role in current cancer treatment; furthermore, it interacts with autophagy (43). Autophagy is involved in a wide variety of physiological and pathological processes and is closely associated cancer $(44,45)$. Under normal circumstances, autophagy clears misfolded proteins and organelles, preventing stress reaction and cancer incidence (46). However, although autophagy is primarily a protective process, it can also promote cancer viability by degrading abnormal proteins and organelles in cancer cells $(44,46)$. Induction of autophagy may affect cancer drug curative effects $(47,48)$. The results of the present study suggest that the inhibition of autophagy induces a statistically significant decrease in viability and apoptosis in A549 cells in response to HCPT treatment. Taken together, the results of the present study lead to a deeper understanding of the molecular mechanisms underlying HCPT-induced autophagy in lung cancer.

In summary, the results of the present study support the hypothesis that autophagy is a survival mechanism for A549 cells in response to HCPT treatment. The results have marked implications because HCPT resistance and 
autophagy are associated with human cancer and resistance to treatment $(1,3,49)$. Therefore, inhibiting autophagy in tumors may be a means to increase the efficacy of anticancer treatment.

\section{Acknowledgements}

The authors thank all members of the Medical Research Center, North China University of Science and Technology. The abstract was presented at the ATS 2017 Conference 19-24 May 2017 in Washington, DC, USA, and published as abstract no. A3124 in Am J Respir Crit Care Med 195 (Suppl 1): 2017.

\section{Funding}

The present study was supported by the North China University of Science and Technology Research (grant no. 201610081026), the Key Projects of Science and Technology Research in Hebei Province (grant no. ZD2017063), the North China University of Science and Technology Research (grant no. X2016026) and the Tangshan International Technological Cooperation Projects (grant no. 14160201B).

\section{Availability of data and materials}

All materials described in the manuscript, including all relevant raw data, will be freely available to any scientist wishing to use them for non-commercial purposes, without breaching participant confidentiality.

\section{Author's contributions}

HW and WT designed the study. YW wrote the manuscript and performed the western blotting. CL conducted the cell culture and performed the cell viability assay. YZ prepared the cell samples for the autophagy assay. HH performed the laser-scanning confocal microscopy. XH prepared the cell samples for the apoptosis assay and performed the imaging. GZ and HL helped to conduct the cell culture and write the manuscript, and all authors read and approved the final manuscript.

\section{Consent for publication}

Not applicable.

\section{Competing interests}

The authors declare that they have no competing of interests.

\section{References}

1. Urasaki Y, Takebayashi Y and Pommier Y: Activity of a novel camptothecin analogue, homocamptothecin, in camptothecin-resistant cell lines with topoisomerase I alterations. Cancer Res 60: 6577-6580, 2000 .

2. Zhang R, Li Y, Cai Q, Liu T, Sun H and Chambless B: Preclinical pharmacology of the natural product anticancer agent 10-hydroxycamptothecin, an inhibitor of topoisomerase I. Cancer Chemother Pharmacol 41: 257-267, 1998.

3. Zhang G, Ding L, Renegar R, Wang X, Lu Q, Huo S and Chen YH: Hydroxycamptothecin-loaded $\mathrm{Fe} 3 \mathrm{O} 4$ nanoparticles induce human lung cancer cell apoptosis through caspase- 8 pathway activation and disrupt tight junctions. Cancer Sci 102 1216-1222, 2011.
4. Nie F, Cao J, Tong J, Zhu M, Gao Y and Ran Z: Role of Raf-kinase inhibitor protein in colorectal cancer and its regulation by hydroxycamptothecine. J Biomed Sci 22: 56, 2015.

5. Liu Z, Zhu G, Getzenberg RH and Veltri RW: The upregulation of PI3K/Akt and MAP kinase pathways is associated with resistance of microtubule-targeting drugs in prostate cancer. J Cell Biochem 116: 1341-1349, 2015.

6. Bian Z, Yu Y, Quan C, Guan R, Jin Y, Wu J, Xu L, Chen F, Bai J, Sun W and Fu S: RPL13A as a reference gene for normalizing mRNA transcription of ovarian cancer cells with paclitaxel and 10-hydroxycamptothecin treatments. Mol Med Rep 11:3188-3194, 2015.

7. Siegel R, Ma J, Zou Z and Jemal A: Cancer statistics, 2014. CA Cancer J Clin 64: 9-29, 2014.

8. Jemal A, Bray F, Center MM, Ferlay J, Ward E and Forman D: Global cancer statistics. CA Cancer J Clin 61: 69-90, 2011.

9. Fu T, Wang L, Jin XN, Sui HJ, Liu Z and Jin Y: Hyperoside induces both autophagy and apoptosis in non-small cell lung cancer cells in vitro. Acta Pharmacol Sin 37: 505-518, 2016.

10. Mizushima N, Yoshimori T and Levine B: Methods in mammalian autophagy research. Cell 140: 313-326, 2016.

11. Baehrecke EH: Autophagy: Dual roles in life and death? Nat Rev Mol Cell Biol 6: 505-510, 2005.

12. Zhang $\mathrm{H}$ and Baehrecke $\mathrm{EH}$ : Eaten alive: Novel insights into autophagy from multicellular model systems. Trends Cell Biol 25: 376-387, 2015.

13. Weckman A, Rotondo F, Di Ieva A, Syro LV, Butz H, Cusimano MD and Kovacs K: Autophagy in endocrine tumors. Endocr Relat Cancer 22: R205-R218, 2015.

14. Djavaheri-Mergny M, Maiuri M and Kroemer G: Cross talk between apoptosis and autophagy by caspase-mediated cleavage of Beclin 1. Oncogene 29: 1717-1719, 2010.

15. Kang R, Zeh HJ, Lotze MT and Tang D: The Beclin 1 network regulates autophagy and apoptosis. Cell Death Differ 18: 571-580, 2011.

16. Pan X, Zhang X, Sun H, Zhang J, Yan M and Zhang H: Autophagy inhibition promotes 5-fluorouraci-induced apoptosis by stimulating ROS formation in human non-small cell lung cancer A549 cells. PLoS One 8: e56679, 2013.

17. Ravikumar B, BergerZ, VacherC, O'Kane CJ and Rubinsztein DC: Rapamycin pre-treatment protects against apoptosis. Hum Mol Genet 15: 1209-1216, 2006.

18. Cui Q, Tashiro S, Onodera S, Minami M and Ikejima T: Autophagy preceded apoptosis in oridonin-treated human breast cancer MCF-7 cells. Biol Pharm Bull 30: 859-864, 2007.

19. Iwamaru A, Kondo Y, Iwado E, Aoki H, Fujiwara K, Yokoyama T, Mills GB and Kondo S: Silencing mammalian target of rapamycin signaling by small interfering RNA enhances rapamycin-induced autophagy in malignant glioma cells. Oncogene 26: 1840-1851, 2007.

20. Cheng Y, Chen G, Hu M, Huang J, Li B, Zhou L and Hong L: Has-miR-30a regulates autophagic activity in cervical cancer upon hydroxycamptothecinexposure. Biomed Pharmacother 75: 67-74, 2015.

21. Desai SD, Reed RE, Babu S and Lorio EA: ISG15 deregulates autophagy in genotoxin-treated ataxia telangiectasia cells. J Biol Chem 288: 2388-2402, 2013.

22. Eskelinen EL, Prescott AR, Cooper J, Brachmann SM, Wang L, Tang X, Backer JM and Lucocq JM: Inhibition of autophagy in mitotic animal cells. Traffic 3: 878-893, 2002.

23. Vilgelm AE, Pawlikowski JS, Liu Y, Hawkins OE, Davis TA, Smith J, Weller KP, Horton LW, McClain CM, Ayers GD, et al: $\mathrm{Mdm} 2$ and aurora kinase a inhibitors synergize to block melanoma growth by driving apoptosis and immune clearance of tumor cells. Cancer Res 75: 181-193, 2015.

24. Zhu M, Xu Y, Ge M, Gui Z and Yan F: Regulation of UHRF1 by microRNA-9 modulates colorectal cancer cell proliferation and apoptosis. Cancer Sci 106: 833-839, 2015.

25. Hamedani FS, Cinar M, Mo Z, Cervania MA, Amin HM and Alkan S: Crizotinib (PF-2341066) induces apoptosis due to downregulation of pSTAT3 and BCL-2 family proteins in NPM-ALK(+) anaplastic large cell lymphoma. Leuk Res 38: 503-508, 2014.

26. Edlich F, Banerjee S, Suzuki M, Cleland MM, Arnoult D, Wang C, Neutzner A, Tjandra N and Youle RJ: Bcl-x(L) retrotranslocates Bax from the mitochondria into the cytosol. Cell 145: 104-116, 2011.

27. Rossé T, Olivier R, Monney L, Rager M, Conus S, Fellay I, Jansen B and Borner C: Bcl-2 prolongs cell survival after Bax-induced release of cytochrome c. Nature 391: 496-499, 1998. 
28. Lalier L, Cartron PF, Juin P, Nedelkina S, Manon S, Bechinger B and Vallette FM: Bax activation and mitochondrial insertion during apoptosis. Apoptosis 12: 887-896, 2007.

29. Guo B, Zhai D, Cabezas E, Welsh K, Nouraini S, Satterthwait AC and Reed JC: Humanin peptide suppresses apoptosis by interfering with Bax activation. Nature 423: 456-461, 2003.

30. Tallman MS: New strategies for the treatment of acute myeloid leukemia including antibodies and other novel agents. Hematology Am Soc Hematol Educ Program: 143-150, 2005.

31. Chen XP, Ren XP, Lan JY, Chen YG and Shen ZJ: Analysis of HGF, MACC1, C-met and apoptosis-related genes in cervical carcinoma mice. Mol Biol Rep 41: 1247-1256, 2014.

32. Yuan Y, Wang H, Wei Z and Li W: Impaired autophagy in hilar mossy cells of the dentate gyrus and its implication in schizophrenia. J Genet Genomics 42: 1-8, 2015.

33. Gewirtz DA: The four faces of autophagy: Implications for cancer therapy. Cancer Res 74: 647-651, 2014.

34. Maiuri MC, Zalckvar E, Kimchi A and Kroemer G: Self-eating and self-killing: Crosstalk between autophagy and apoptosis. Nat Rev Mol Cell Biol 8: 741-752, 2007.

35. Maiuri MC, Le Toumelin G, Criollo A, Rain JC, Gautier F, Juin P, Tasdemir E, Pierron G, Troulinaki K, Tavernarakis N, et al: Functional and physical interaction between Bcl-XL and a BH3-like domain in Beclin-1. EMBO J 26: 2527-2539, 2007.

36. Yorimitsu T and Klionsky DJ: Autophagy: Molecular machinery for self-eating. Cell Death Differ 12 (Suppl 2): S1542-S1552, 2005.

37. Mizushima N, Levine B, Cuervo AM and Klionsky DJ: Autophagy fights disease through cellular self-digestion. Nature 451: 1069-1075, 2008.

38. Schreiber RD, Old LJ and Smyth MJ: Cancer immunoediting: Integrating immunity's roles in cancer suppression and promotion. Science 331: 1565-1570, 2011.

39. Michaud M, Martins I, Sukkurwala AQ, Adjemian S, Ma Y, Pellegatti P, Shen S, Kepp O, Scoazec M, Mignot G, et al: Autophagy-dependent anticancer immune responses induced by chemotherapeutic agents in mice. Science 334: 1573-1577, 2011.
40. Cheng YX, Zhang QF, Pan F, Huang JL, Li BL, Hu M, Li MQ and Chen Ch: Hydroxycamptothecin shows antitumor efficacy on HeLa cells via autophagy activation mediated apoptosis in cervical cancer. Eur J Gynaecol Oncol 37: 238-243, 2016.

41. White E and DiPaola RS: The double-edged sword of autophagy modulation in cancer. Clin Cancer Res 15: 5308-5316, 2009.

42. Lin L and Baehrecke EH: Autophagy, cell death, and cancer. Mol Cell Oncol 2: e985913, 2015.

43. Bailly C: Homocamptothecins: Potent topoisomerase I inhibitors and promising anticancer drugs. Crit Rev Oncol Hematol 45 91-108, 2003.

44. Levine B and Kroemer G: Autophagy in the pathogenesis of disease. Cell 132: 27-42, 2008

45. Yan J, Yang H, Wang G, Sun L, Zhou Y, Guo Y, Xi Z and Jiang X: Autophagy augmented by troglitazone is independent of EGFR transactivation and correlated with AMP-activated protein kinase signaling. Autophagy 6: 67-73, 2010.

46. Levine B and Klionsky DJ: Development by self-digestion: Molecular mechanisms and biological functions of autophagy. Dev Cell 6: 463-477, 2004.

47. Amaravadi RK, Lippincott-Schwartz J, Yin XM, Weiss WA, Takebe N, Timmer W, DiPaola RS, Lotze MT and White E: Principles and current strategies for targeting autophagy for cancer treatment. Clin Cancer Res 17: 654-666, 2011.

48. Sui X, Chen R, Wang Z, Huang Z, Kong N, Zhang M, Han W, Lou F, Yang J, Zhang Q, et al: Autophagy and chemotherapy resistance: A promising therapeutic target for cancer treatment. Cell Death Dis 4: e838, 2013.

49. Liu Z, Shi A, Song D, Han B, Zhang Z, Ma L, Liu D and Fan Z Resistin confers resistance to doxorubicin-induced apoptosis in human breast cancer cells through autophagy induction. Am J Cancer Res 7: 574-583, 2017.

This work is licensed under a Creative Commons Attribution-NonCommercial-NoDerivatives 4.0 International (CC BY-NC-ND 4.0) License. 